-

\title{
Transport-Diffusion Comparisons for Small Core LMFBR Disruptive Accidents
}

\author{
E. T. Tomlinson
}


ORNL/CSD/TM-38 .

Distribution Categories

UC-79d, UC-79p

Contract No. W-7405 eng 26

COMPUTER SCIENCES DIVISION

TRANSPORT-DIFFUSION COMPARISONS FOR

SWALL CCRE LMFBR DISRUPTIVE ACCIDENTS*

E. T. Tomlinson

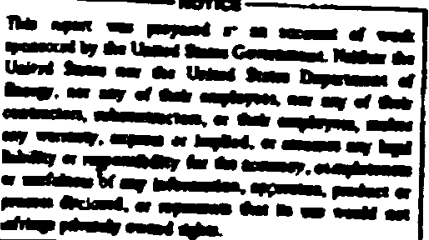

${ }^{\star}$ Research sponsored by ORNL Neut-üi Fhysics Division

Date Published - November 1977

UNION CARBIDE CORPOPATION, NUCLEAR DIVISION

operating the

Oak. Ridge Gaseous Diffusion Plant - Oak Ridge Nditional Laboratory

Oak Ridge $Y-12$ Plant

for the

DEPARTMENT OF ENERGY 


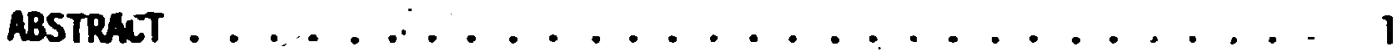

I.' INTROOUCTION ..................... 1

II. THE CROSS SECTIONS .................. 2

III. THE CALCULATIONAL METhGOS .............. 4

A. Diffusion Theory ................ 4

B. Transport Theory ................ 5

C. Perturbation Theory........... 6

IV. THE HOMGENEOUS CORE .................. 7

A. Reactor Configurations ............. 7

Case 1 - The Reference Core ........... 8

Case 2 - The Sodiun Void Model ......... 8

Case 3 - The Post Clad Motion/Pre Fuel

Motion Model ............... 9

Case 4 - The Post Fiel Hotion/Pre

Shutdown Model ............... ic

Case 5 - The Post Fuel Motion Model . . . . . . . 15

B. The Numerical Results and Analys is ......... 15

Calculated keff's . . . . . . . . . . . 18

Reactivity Changes ................. 21

V. THE HETEROGENEOUS CORE ................ . . 26

A. Reactor Configurations ............. 26

Case 1 - The Reference Assenbiy . . . . . . . . 27

Case 2 - The Voided Driver Model . . . . . . 27

Case 3 - The Voided Blanket Mode!. . . . . . . . 28

B. Numerical Results and Analyses .......... 30

VI. - CONCLUSIONS . . . . . . . . . . . . 33

VII. ACKNOHLEDGMENTS .................. 36

VIII. REFERENCES ................... 37

APPENDIX ......................... 41

APPENDIX REFERENCES .................... . . 47 
TRAYSPORT-DIFFUSION COIPARISONS FOR

SMALL CORE LIFBR DISRUPTIVE ACEIDENTS

\author{
E. T. Tonlinson
}

\begin{abstract}
A number of numerical experiments were performed to assess the validity of diffusion theory for calculating the reactivity state of various small core LAFBR disrupted gecmetries. The disrupted configurations correspond, in general, to various configurations predicted by SAS3A for transient undercooling (TUC) and transient overpower (IOP) accidents for homogeneous cores and to the ZPPR-7 configurations for heterogeneous core. In all TUC cases difiusion theory was shown to be inadequate for the calculation of reactivity changes during core disassembly.
\end{abstract}

\title{
I. INTRODUCTION
}

The decermination of situations for which diffusion theory is valid is one of the classic questions in reactor physics. There exists a certain class of problems for which diffusion theory is inapplicable, such as the calculation of the neutron flux in voids. These calculations can best be done by solving the neutron transport equation. There is, however, a range of problems for which it is difficult to a priori determine the validity of diffusion theory, such as partially disassembled homogeneous reactor cores and heterogeneous (parfait) reactor core designs.

The objective of this study is to examine the aforementioned situations and to determine where diffusion theory no longer yieids acceptable results either directly, through the use of standard biasing tectiniques, or through the use of first-order perturbation theory. To 
this end, the project was divided into two sections. The , irst section consists of an analysis of various snapshot models of a disruptzed $330 \min (e)$ hemogeneous Ifquid metal fast breeder reactor (LFBR) core, using botn diffusion and transport theory and perturbation theory. The models chosen were sifilifar to those preficted by the SAS3A' accident analysis core, but somat exaggerated. The large recitivity insertions predicted, would in reality not occur in an LAFBR core due to the effects of such pinenomenon as Doppler brpadening etc. The second section consists of $\because-$.

in analyris of a 350 mile; heterogeneous core. The yeometric configurations considered in this section were simflar to those occurring in the Zero Power Plutoniun Reactor (2PPR-7) ${ }^{2}$ experimental mock-up of the $\mathrm{Cl}$ inch River Breeder Reactor Plant (CRBRP) al ternate fuel managenent schere (heterogeneous) core. ..

\section{THE CROSS SECTIONS}

A 7 group ${ }^{3}$ macroscoptic cross section library was created for use in the disrupted core neutronic analysis as well as for shutdown core physics studies. This library was collapsed from the $i 26$ group psuedo compositionindependent neutron library." Prior to colle.psing the cross sections the energy self-shielding effects in the macros copic cross sections were accounted for by utflizing the homogeneous region Bonderanko treatment as it is coded into SPHINX. 5

- The XSDRNPM module of the AMPX6 code system was used to collapse the fine group seiff shielded lifbrary to a 7 group $P_{3}$ library. The one-dimensional core model used for the calculation of the flux used in the collapse, is shown in Frgure 1. The energy boundaries for the 7 group llibrary are given l', Table I. 


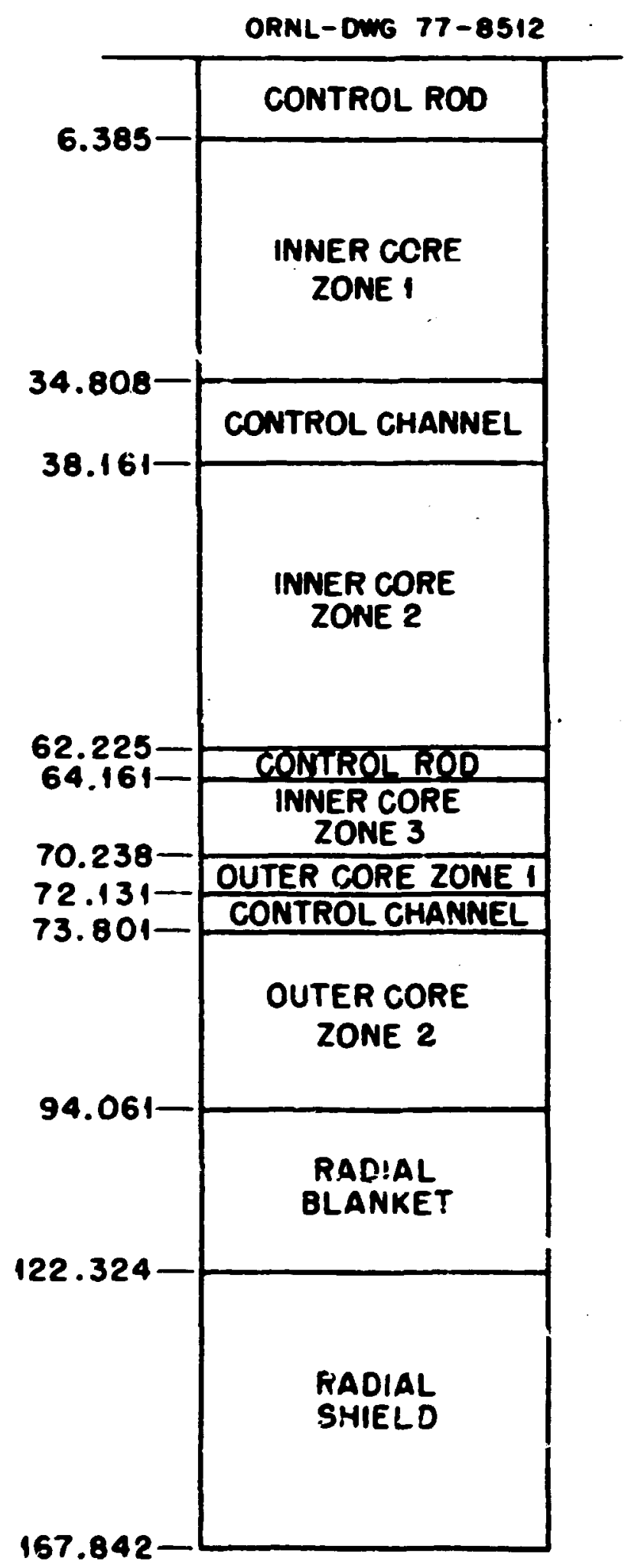

Fig. 1. The One-Dimensional Model of the CRBR Core Used For Cross Section Processirz. 
Table I. The Energy Boundaries for Seven Group Disrupted Core Cross Section Library

\begin{tabular}{cc}
\hline Group & Upper Energy Boundary (ev) \\
\hline 1 & $1.7333+07$ \\
2 & $8.1873+06$ \\
3 & $5.4881+06$ \\
4 & $2.4660+06$ \\
5 & $4.9787+05$ \\
7 & $1.2341+03$ \\
7 & $4.1399-01$ \\
& $1.0000-05$ \\
\hline
\end{tabular}

A 7 group, transport corrected, P, macroscopic library was created for use in the diffusion calculations. The "inflow approximation" in the AXIX? code was ised for the calculation of the transport cross section.

Since these studies were scoping and comparative in nature, the cross sections were not reweighted for the heterogeneous core calculations, nor were the 2PPR-7 atom densities employed. Blanket and core materials that were generated for the homogeneous cases were merely interchanged.

\section{THE CALCULATIONAL METHODS}

\section{A. Diffusion Theory}

The diffusion calculations perfonmed for this study were all done using the DOT3.5 $5^{8}$ discrete-ordinate code. Each calculation was considered io be converged when the fractional error in the keff eigenvalue was less thian $1.0 \times 10^{-4}$ and the point-wise error in the scaiar flux was less than 
$1.0 \times 10^{-4}$. A typical calculation required 20-30 minutes of computing time on the IBM 360/91. Since D0T3.5 does not employ any convergence acceleration scheme on outer iterations and only non-sophisticated overrelaxation on the inner iterations, shorter computing times would be expected using codes such as VENTURE," DIFF30,10 or FX2.11 Central processor unit times for the "fine" mesh diffusion calculations were scmewhat longer (approximately $90 \mathrm{~min}$ ). The details of these cases are discussed later in this report.

\section{B. Transport Theory}

The first attempt to perform the transport calculations for this study was nade using the D0T3.5 discrete ordinates code. Initial analysis indicated that the linear/step diamond difference ${ }^{8}$ schemes in D0T3.5 could not be converged to the desired level. Model oscillations, i.e., cyclic switching between the linear and siep models led to significant errors in the calculated Keff's and consequently in the reactivity changes. The point-wise angular fluxes could not be converged to less than $1.0 \times 10^{-2}$ in some regions. As a result the decision was made to employ the newly developed DOT-4 ${ }^{12}$ discrete-ordinates code which has a "super-weighted" difference scheme that allows tighter convergence, see Appendix. The use of this difference scheme allowed the point-wise angular fluxes to be converged to a fractional deviation of less than $1.0 \times 10^{-4}$ and the point-wise fission source to be converged to less than $1.0 \times 10^{-3}$.

The variations seen by switching differencing schemes were significant. The 1 inear/step difference schemes calculated a sodium void worth for Case 1 , described in the next section, of $+0.318 \$$ while the super-weighted 

$F\left\{\begin{array}{l}=\text { unperturbed fiss fon operator (first order) } \\ =F+\delta F=\text { perturbed fission operator (exact) }\end{array}\right.$

The brackets in equation (1) indicate integration over all phase space. The pertarbation results were calculated using a number of code modules ${ }^{13-15}$ developed for use with the DOT series of codes. These nodules allow the calculation of both first order and exact perturbation reactivity changes based on either transport or diffusion theory.

\section{THE HOMOGENEOUS CORE}

The first section of this report dezls with exaggerated inpothetical accident sequences similar to those that have been postulated for the 350 (e) homogeneous LMFBR core design. ${ }^{16}$ Included in this section are the various disrupted configurations that were considered and the numerical results that were obtained.

\section{A. Reactor Configurations}

Five "sniapshot" configurations were chosen for detailed nautronic analysis. Each configuration approximated, within the limits of $R-Z$ geometry, a distinct phase in either the unprotected transient overpower (TOP) or transient undercooling (TUC) accident scenario. These configurations were defined as follows:

Case 1 - normal beginning of life (BOL) $350 \mathrm{MW}(e)$ core, Case 2 - initial sodium voiding phase of a TUC accident,

Case 3 - post-clad motion/pre-fuel motion phase of a TUC accident, 
Case 4 - post-fiel motion/pre-shutdown phase of a TUC accident, Case 5 - post-fuel motion phase of a TOP accident.

\section{Case 1 - The Reference Core}

The reference $\mathrm{BOL}$ core is depicted in Figure 2. The calculational wodel was extended through the shield in the radial direction $(167.842 \mathrm{~cm}$ fram the centerline) where a non-return boundary condition was imposed. The axial model extended from the non-return boundary at the lower edge of the lower attachment upward through the upper fission gas plenum, a -distance of $367.436 \mathrm{~cm}$ to another non-return boundary. The interior mesh spacing and zone map are shown in Figure 3. A total of 3672 mesh points were used to describe this and all subsequent disrupted geometries.

An extra row of control rods was included in the model presented in Figure 2. This was done in an attempt to model the partialiy inserted control rods on the corners of the hex that approximate the inner core. The safety rods on the flats of this hex were parked in the upper axial bianket. This is a staridard modeling technique employed by Westinghouse (H-ARD) in modeling of the CRBRP.

\section{Case 2 - The Sodium Void Model}

The intent of the sodium void configuration was to model the initial phases of sodium voiding. In this configuration the sodium was voided from the high power to flow ratio channels, namely the center most subassemblies and the first row of subassemblies in the outer core. The voiding was assumed to occur in the active core region and to extend up through the upper axial blanket. The material changes and the zones 


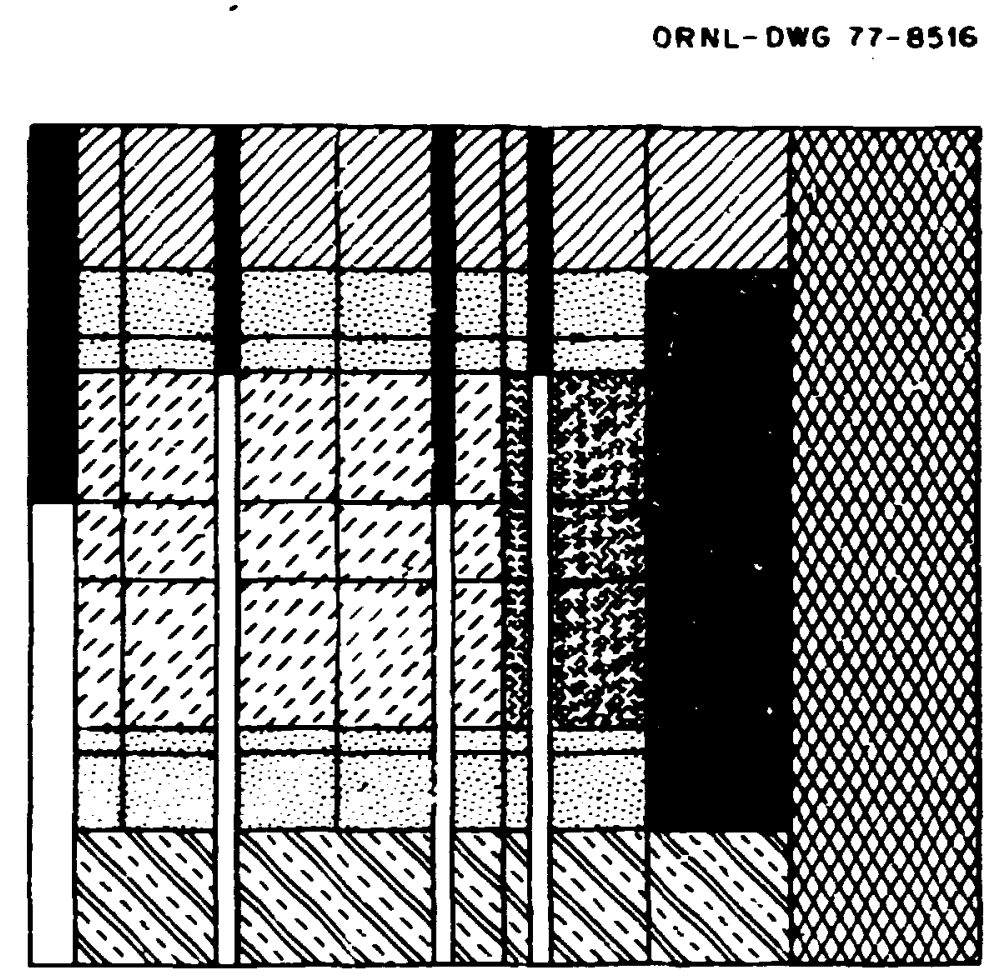

$E 3$ INAER CORE

axial BLANKET

00 RADIAL SHIELO

W lomer attachement

$\square$ CONTROL Chanyel
OUTEK CORE

zadial blamket

$Z_{\text {fission gas ilenum }}$

CONTROL ROE

Fig. 2. Material Map for the Case 1 Disrupted Configuration?.

involved in this perturbation are presented in Table II and illustrated in Figure 4.

Case 3 - The Post Clad Motion/Pre Fuel Motion Model.

The third disrupted configuration is described in Table II and illustrated in Figure 5. This configuration was representative of the core after a Targe fraction, $78 \%$, of the inner core has voided in addition to the first row of subassemblies in the outer core. The steel clad in the 


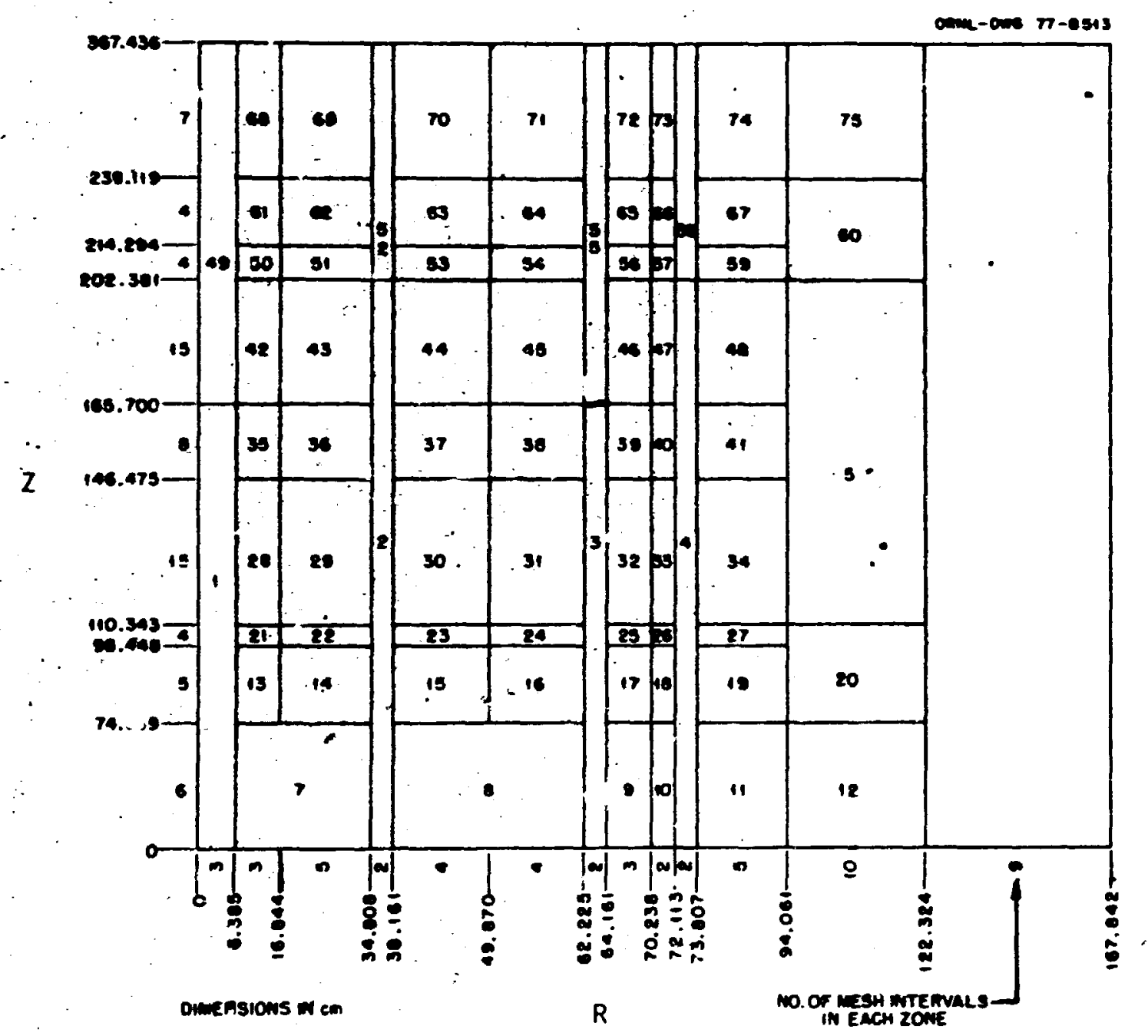

Fig. 3. Mesh Spacing and Zone Map for a 350 MN(e) LMFBR Core.

first three rows of subassemblies in the inner core and the first row of subassenbifes in tile outer core was assumed to have melted throughout the entire active core region. This material was then postulated to move upward and downward into the upper and lower axial blankets. Approximately $40 \%$ of the clad was assumed to freeze uniformly in the lower $11.913 \mathrm{~cm}$ of the upper axial blanket and $60 \%$ in the upper $11.895 \mathrm{~cm}$ of the lower axial blanket. 
Table II. Disrupted Core Configurations

\begin{tabular}{|c|c|c|c|}
\hline Problem ID & Effect of Interest & Quantity & Zones Involved \\
\hline Case 1 & Reference. & - & \\
\hline Case 2 & Sodiun void & $100 \%$ from & $\begin{array}{l}28,29,35,36,42,43,50,51 \\
61,62 \\
33,40,47,57,66\end{array}$ \\
\hline \multirow[t]{7}{*}{ Case 3} & Sodium void & $100 \%$ from & $\begin{array}{l}21,22,23,26,28,29,30,31,33, \\
35,36,37,38,40 \\
42,43,44,45,47,50,51,53,54, \\
57,61,62,63,64,66\end{array}$ \\
\hline & Move SS & $100 \%$ from & $28,29,30,35,36,37,42,43,44$ \\
\hline & & $40 \%$ to & $50,51,53$ \\
\hline & & $50 \%$ to & $21,22,23$ \\
\hline & Move SS & $100 \%$ from & $33,40,47$ \\
\hline & & $40 \%$ to & 57 \\
\hline & & $60 \%$ to & 26 \\
\hline \multirow[t]{10}{*}{ Case 4} & Same as 3 & & \\
\hline & Void Fuel & $\begin{array}{l}100 \% \text { from } \\
5 \% \text { to }\end{array}$ & $\begin{array}{l}42, \\
50,\end{array}$ \\
\hline & . & $80 \%$ to & 35 \\
\hline & & $10 \%$ to & 28 \\
\hline & & $5 \%$ to & 21 \\
\hline & Void Fuel & $100 \%$ from & 47 \\
\hline & & $5 \%$ to & 57 \\
\hline & & $80 \%$ to & 40 \\
\hline & & $10 \%$ to & 33 \\
\hline & & $5 \%$ to & 26 \\
\hline \multirow[t]{4}{*}{ Case 5} & Move Fuel & $20 \%$ from & $28,35,42$ \\
\hline & & $20 \%$ to & 61 \\
\hline & & $20 \%$ from & $33,40,47$ \\
\hline & & $20 \%$ to & 66 \\
\hline
\end{tabular}

₹ See Figure 3. 


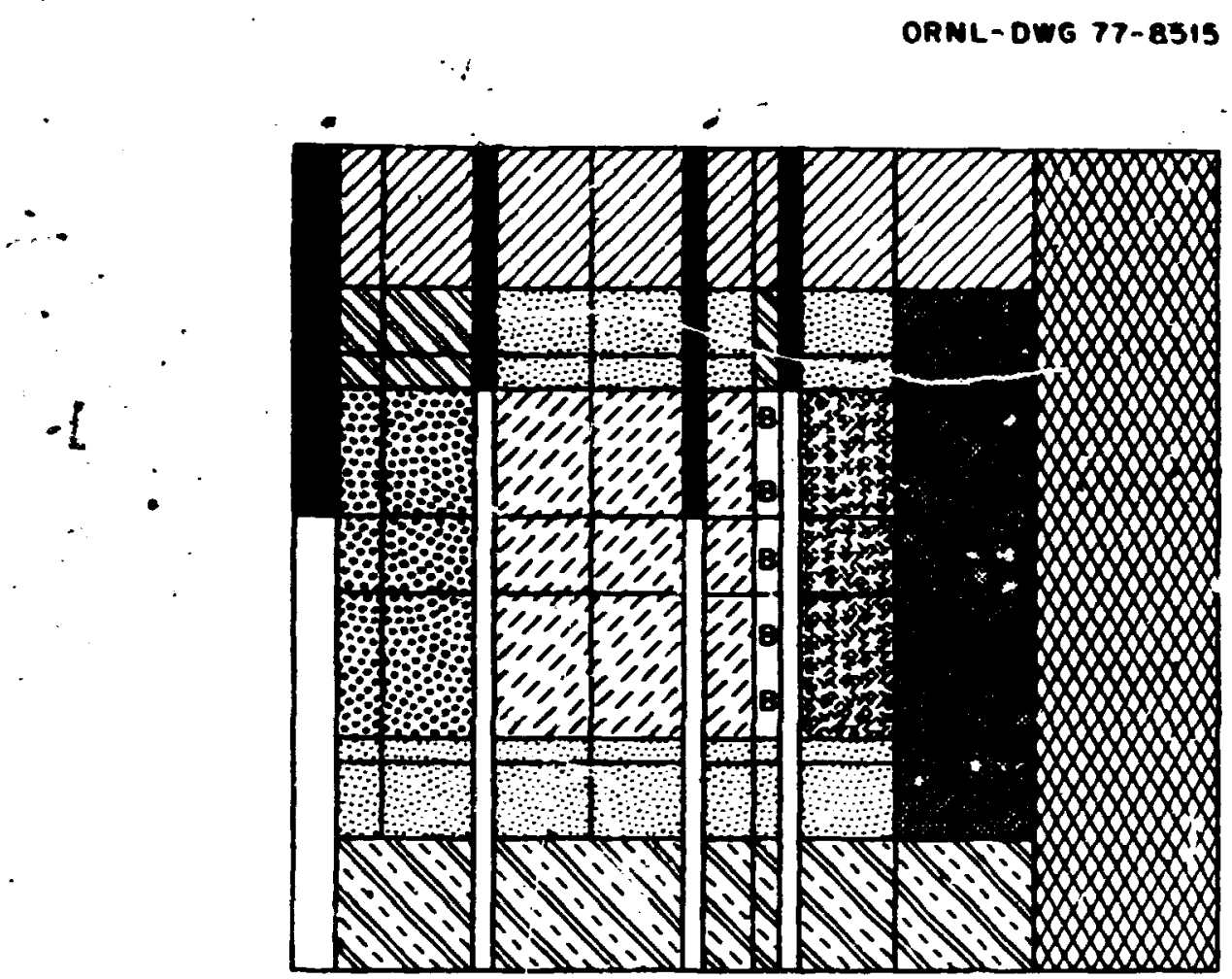

- EJ InNer core

Di AXINL bLAMKet

8 RADIAL SHIELD

Nlomer attachent

$\square$ Control Chaniwel

B. SODIUM VOIDED OUTER CORE
OUTER CORE

3 radial blanket

D fission gas plenta

comral rOD

SOPIUM VOIDED INMER CORE

SODIUM VOIDED AXIAL BLANKET

Fig. 4. Material Map for the Case 2 Disrupted Configuration.

Case 4 - The Post Fuel Motion/Pro Shutdown Model

The fourth disrupted configuration was described in detail in Table II and 11 lustrated in Figure 6 . This configuration was representative of a core shortly after the inftiation of fuel slumping in the center six subassemblies of the inner core. The upper $36.681 \mathrm{~cm}$ of the unclad fuel 
ORNL-DWG 77-8517

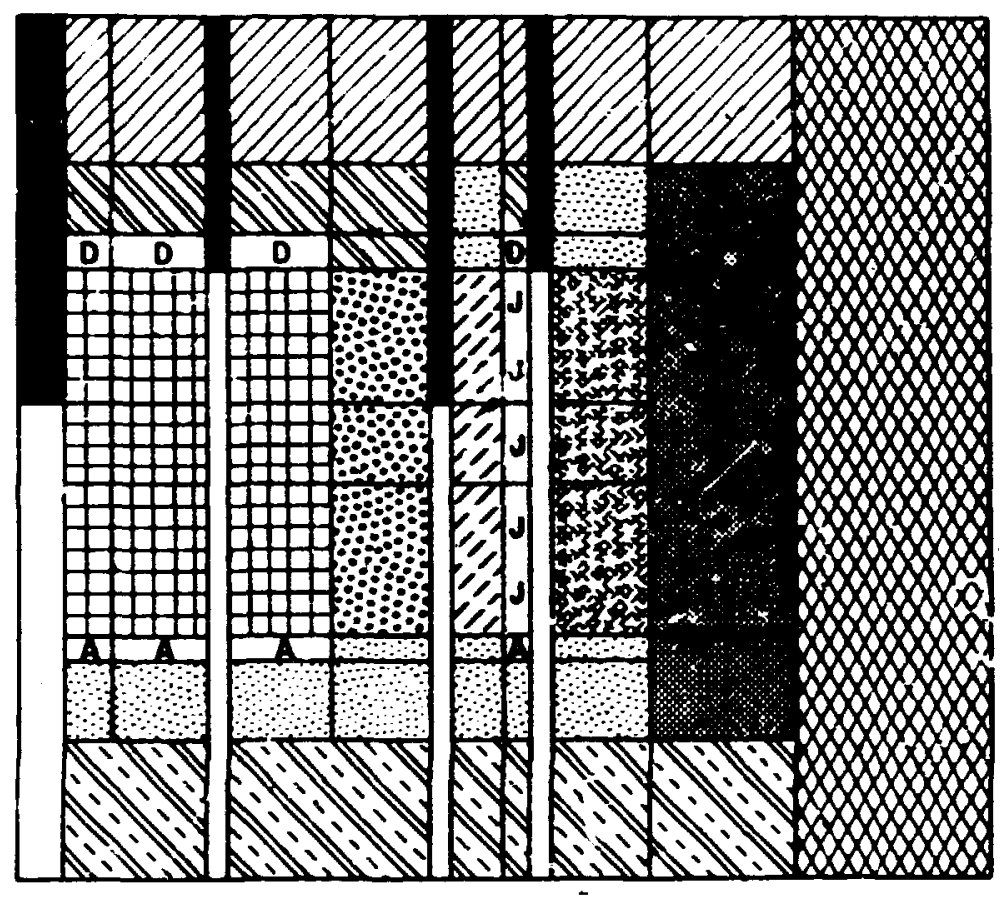

ZIMER CORE

AXIAL BLAMKET

RADIAL SHIELO

Lower at:achent

$\square$ CONTROL CHAMNEL

A 60: STE! + Axial BLAMKET

SOOILM ANO CiEEL VOIDED IMNER CORE

D40\% STEEL + SODIUM VOID AXIAL BLANKET
OUTER CORE

Radial blamket

Z-issiom Gas plemum

CONTROL ROD

SODIU VOIDED IMNER CORE

$\mathbb{N}$ sootum voloed axial blanket

J SOOIUM ANO STEEL VOIDED OUTER CORE

Fig. 5. Material Map for the Case 3 Disrupted Configuration.

mas assumed to redistribute itself uniformly in the lower portion of the subassembly, the lower axial blanket arid the upper axial blanket. The majority of the fuel was assumed to sl uin under the force of gravity redistributing itself as follows: $80 \%$ in the center $19.225 \mathrm{~cm}$ of the 
active fuel region, $10 \%$ in the lower $36.132 \mathrm{~cm}$ of the active fuel region and $5 \%$ in the upper $11.895 \mathrm{~cm}$ of the lcxer axial blanket. The remaining 5\% was postulated to move upwari and freeze on ur near the steel plug in lower $11.913 \mathrm{~cm}$ of the upper axjal blanket.

\section{Case 5 - The Post Fuel Motion Model}

The fifth and final disrupted configuration was representative of the post TOP accident fuel relocation and is described in Table II and illustrated in Figure 7. It was postulated that $20 \%$ of the fuel was expelled from: the fuel pins in the center subassenblies of the inner core and the first row of subassemblies in the outer core. It was then swept up and out of the core into the upper $23.825 \mathrm{~cm}$ of the upper axial blanket, where it was assumed to freeze. The steel clad and sodium in the axial blanket were assumed to rimain in place.

These five particular disrupted configurations were chosen to be representative of the spectrum of material redistribution in severe core disruptive arcidents. They by no means model all the possible nor necessarily the most reactive situations.

B. The Numerical Results arid Analysis

Three discrete ordinate transport theory $k_{\text {eff }}$ eigenvalue calculations $\left(S_{6} P_{3}, S_{4} P_{3}, S_{4} P_{0}\right)$, were performed using various angular quadratures and scattering cross section expansions in order to access the effects of internal voids and anisotropic scastering. For all the cases examined no significant change was observed by varyirg the order of scattering 


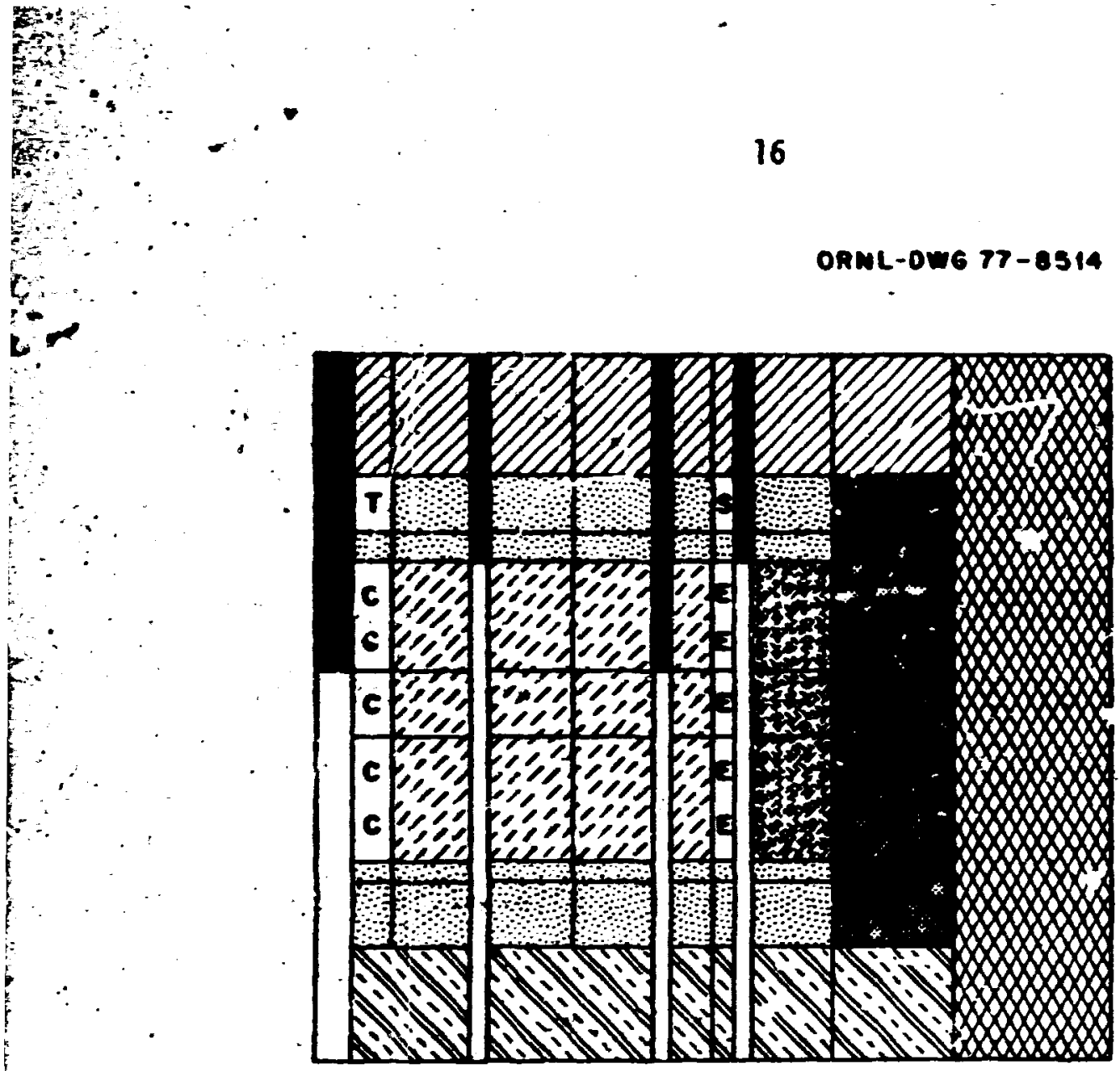

Ei InEER core

- TaxinL BLankit

38 enotal shitslo

Ni acer attachanemt

$\square_{\text {control chimel. }}$

E LOM FUEL DONSITY OUTER CORE

5 AXINL BLANIET + OUTER CORE FUEL PLUG
筆; OUTER CORE

Radial blawret

$\square$ fission gas plemun

CONTROL RDO

C] LON FUEL OENSITV IMXER CORE

0 AXIML BLANKET + INANER CORE FUEL PLUG

Fig. 7. Material Map for the Case 5 Disrupted Configuration.,

or the quadrature over the range cited above. A set of $S_{2} P_{0}$ calculations, not presented here, snowed up to a $0.32 \%$ under prediction in $k_{e f f}$ when compared to the $S_{4} P_{0}$ results.

In order that the initial diffusion theory calculation proceed, a transport cross section of $1.0 \times 10^{-4}$ was assumed for the voided regions in 
Case 4. This led to an inordinately large diffusion coefficient which grossiy overpredicted the neutron leakage from the core region into the axiál blanket regions where neutrons were less inportant and consequently an ulderprediciton of $k_{\text {eff }}$ resulted. Further diffusion calculations were performed to assess tire effects of the assumed value of the diffusion coefficient on keff.

The dependence of $k_{\text {eff }}$ on the value chosen for the diffusion coefficiesit in the internaliy veided regions is shown in figure 8 . The calculated multiplication factor is extremely sensitive to the choic: of fiffusion coefficients even though the voided region represented only $0.74 \%$ of the active core region. An investigation of the shape of the cirve in Figure 8 revealed that for small values of the diffusion coefficient, D, the curve approximates the shape corresponding to Equation (1).

$$
k \propto \frac{k^{\infty}}{1+B^{2} D / \Sigma a}
$$

where the terms have their standard definitions. As the value of the diffusion coefficient was increased the diffusion length, $\frac{0}{\sum \nexists 1 / 2}$, also increased. Corisequently, the enitial variation of the flux through the void in the axial direction became flat while the radial component remained virtualiy unchanged. This implied that the axial current, which was proportional to $\nabla_{\phi}$, approached zero and therefore the axial $D B^{2}$ approached zero. As a result, Equation (1) became a constant which explains the flattening of the curve for large diffusion coefficients.

A more rational approach for changing a diffusion coefficient was based on the dśsumption that the transport mean free path can be approximated by the mean cinord length of the voided region, Equation (2). 


$$
\bar{k}=\frac{4 V}{\$}
$$

$V$ is the volume of the void and

$S$ is the surface area of the void.

- The mltip!isation factors calculated using this approach are shown in Figim - id in Table III. This approximation y!elded good results compared to the expected value based on transport calculations (within $0.10 \%$ of the keff value needed to predict the same reactivity change as predicted ty transport theory). Al though the use of the mean chord length in the void resulted in a substantial improvement in the eigenvalue calculated using diffusion theory significant errors in the pointwise fluxes persisted.

\section{Calculated keff's}

The keff eigenvalues caiculated using discrete ordinate transport theory, diffusion theory, and Monte Carlo are presented in Table III. A comparison of the Keff's calculated using transport theory indicates that. the effect of increasing either the number of angles in the quadrature or the order of scattering has little effect $(<0.15 \%)$ on the results.

The' adequacy of the mesh was examined by comparing the $k_{e f f ' s}$ calculated with the Monte Carlo code KENO ${ }^{17}$ with their corresponding DOT 4 values. 


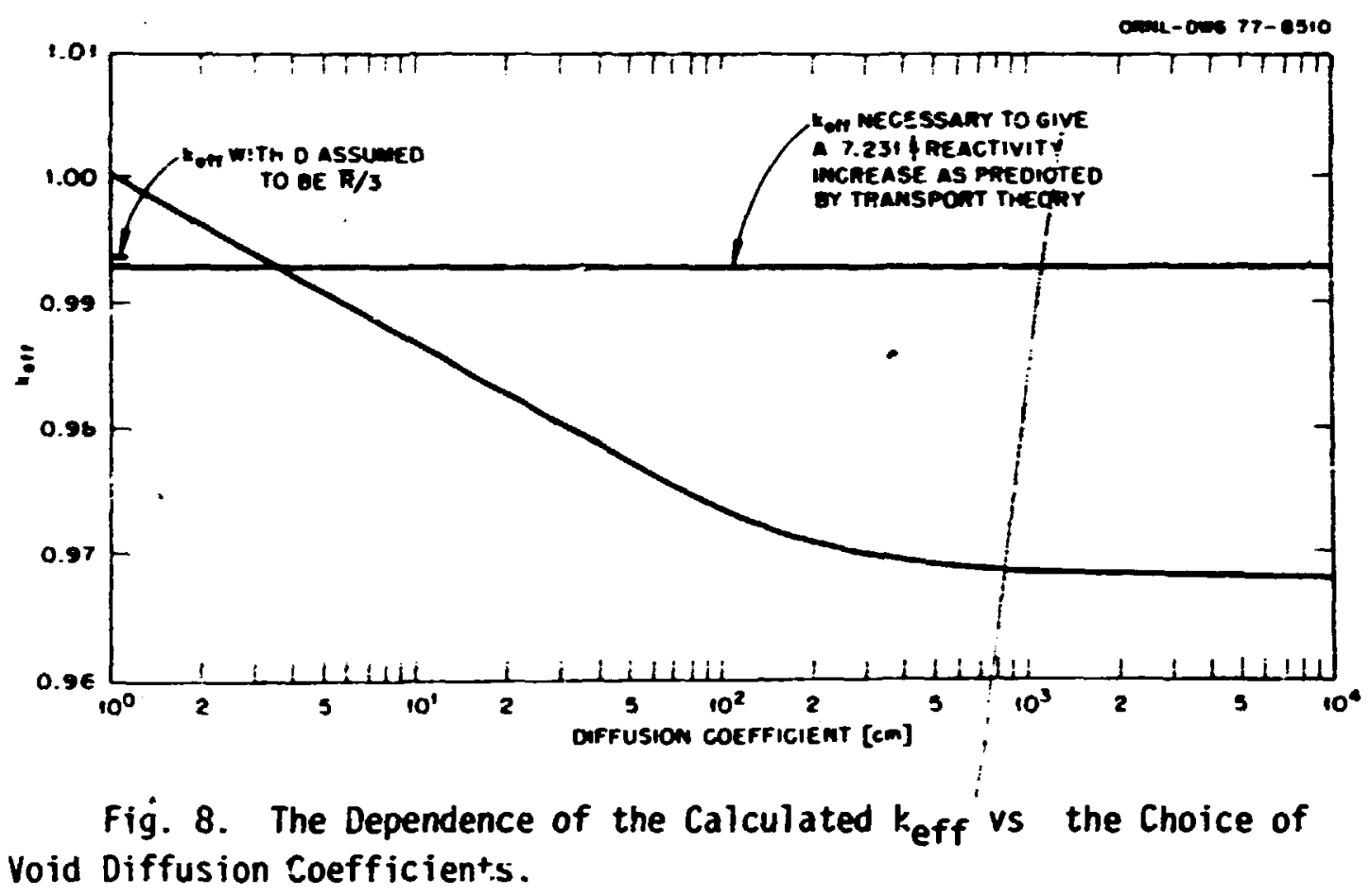

Table III. Calculated $k_{\text {eff }}$ for the Various Disrupted Core Conftgurations

\begin{tabular}{|c|c|c|c|c|c|c|c|}
\hline & \multicolumn{2}{|c|}{ Super-lveighted } & \multirow{2}{*}{$\frac{\text { Linear/Step }}{S_{1} P_{3}}$} & \multirow{2}{*}{$\frac{\text { Super-weighted }}{S_{4} P_{0}}$} & \multirow{2}{*}{$\begin{array}{l}\text { Coarse Mesh' } \\
\text { Diffusion }\end{array}$} & \multirow{2}{*}{$\begin{array}{l}\text { Fine Mesh } \\
\text { Diffusion }\end{array}$} & \multirow{2}{*}{ Keno $P$. } \\
\hline & $S_{6} P_{3}$ & $S_{4} P_{3}$ & & & & & \\
\hline Cose: & 0.98579 & 0.985950 & 0.98529 & 0.987033 & 0.970650 & 0.967040 & $0.98390=0.00255$ \\
\hline Case 2 & 0.985893 & 0.986057 & 0.98628 & 0.987215 & 0.969881 & & \\
\hline Case 3 & 1.00017 & 1.00053 & & 1.00165 & 0.979977 & & \\
\hline Case 4 & 1.00881 & 1.00915 & 1.00877 & $i .01036$ & $\begin{array}{l}0.993463^{3} \\
0.968476^{\circ}\end{array}$ & $\begin{array}{l}0.989108^{\prime} \\
0.963693^{\circ}\end{array}$ & $1.00529: 0.00293$ \\
\hline Case 5 & 0.979032 & 0.979203 & & 0.990218 & 0.963420 & & \\
\hline
\end{tabular}

$154 \times 68$ mesh.

$2108 \times 136$ mesh.

'D $=\bar{R} / 3 \mathrm{~cm}$

ro $23333.33 \mathrm{~cm}$ in vold 
This was done only for the most severely. disrupted (most heterogeneous) configuration since this was where inadequacies in the mesh would most likely have occured. The COT-4 results were in excellent agreearent with the Monte Carlo results (within 20) thus providing a degree of confidence in the riesh used in the transport calculations. The linear/step model calculations are presented here for completeness only and will not be considered further for reasons diseussed in Section III of this report.

Further examination of Table III indicated that diffusion theory consistently underpredicted $k_{\text {eff }}$ from $1.62 \%$ for Case 5 , to $2.06 \%$ for Case 3. Compared to transport theory, there was a $1.5 \%$ underprediction of $k_{\text {eff }}$ for the reference Case 1. The results for Case 4 were purposely deleted from this comparison because of the arbitrary choice of diffusion coefficients in the voided regions. The percent underprediction in keff could have been much larger if these results were included.

A "îne mesh" diffusion calculation was performed on both the Case 1 and Case 4 disrupted configurations. The fine mesh was defined by uniformly doubling the original mesh. niffusion coefficients of 3333.33 and $\bar{R} / 3$ were assumed for the in-core volds. Based on these cases there did not appear to be any significant advantage in using the fine mesh for the diffusion calculations and the remainder of the configurations were calculated using. "coarse mesh" diffusion theory.

Diffusion theory's continuous underprediction of keff was caused by an overprediction of the neutron leakage from the active core zone. The neotron leakage out of the core at the "pper core/axial blanket interface near the core center was calculated to be approximately 15\% higher in a diffusion theory than calculation in an equivalent transport calculation 
for the reference core. The magnitude of this discrepancy increased as the density of the core zone decreased (i.e. the diffusion coefficient increased). Consequently, no single bias factor could a priori be derived wich, wher: appliad to the diffusion theory results, would yield equivalent transfort results.

\section{Reactivity Changes}

Behavior similiar to that observed for the multiplication factors was ubserved for tha calculated reactivity changes between configurations, Table IV. These reactivity changes were calculated using the direct $k$ difference techniques.

Table IV. Calculated Rectivity Changes for the Various Disrupted Configurations $80[\$]$

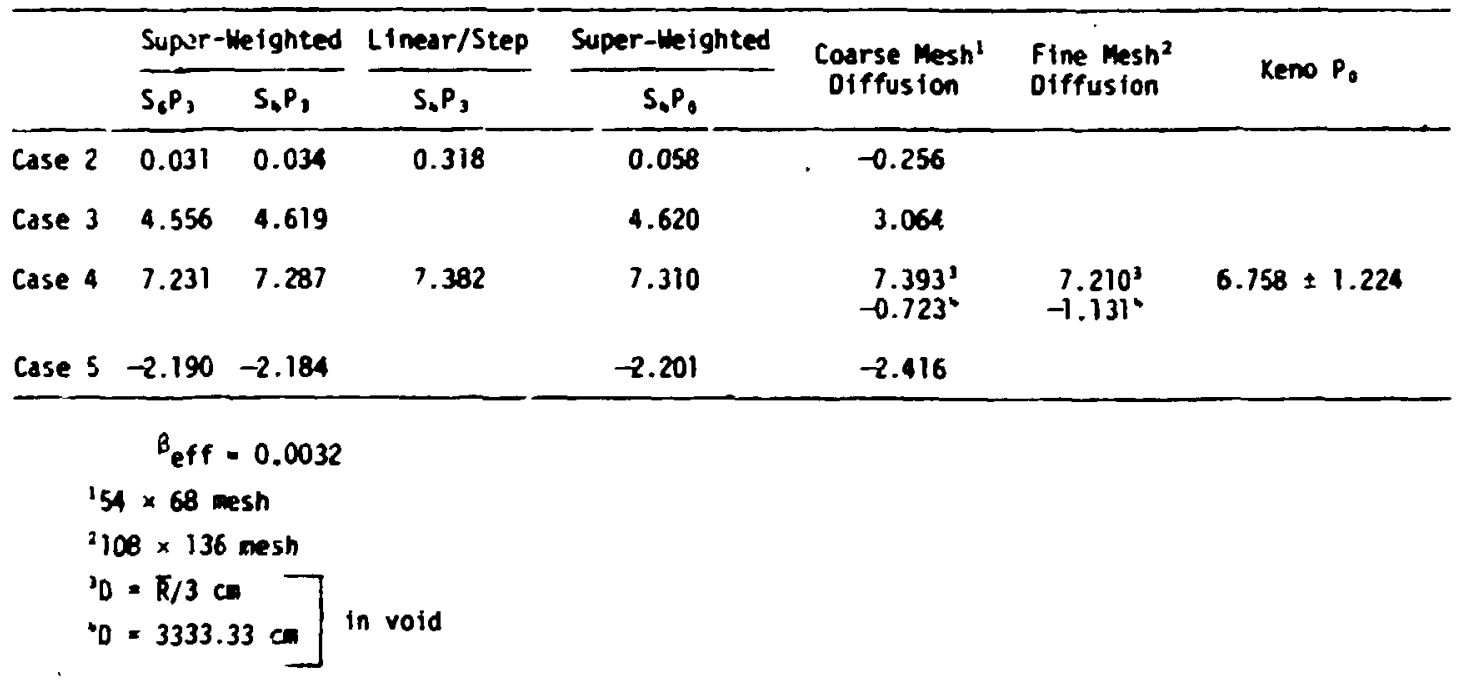

Diffusion theory consistently predicted the system to be less reactive than transport theory. Unfortunately this was always in the non-conservative direction. As was the case in the keff calculat the majority of the error in the calculated reactivity change was $1 .$. the calculation of the Peakage component. 
- The reactivity changes calculated using transport theory were all in excellent agreewent with each other (within a fer cents) indicating that neutron streaming and anisotropic scattering could be accounted for in these nodels by using low order transport methods such as $\mathrm{S}_{4} \mathrm{P}_{0}$. The $S_{2} P_{0}$ results underpredict the reactivity change by as much as $0.44 \$$. The discrete ordinate results lie within 1 o of the Monte Carlo calculated reactivity change, which gave an air of confidence to the results.

. A closei comparison of the difiusion and transport, results revealed that the underprediction of $5 p$ ranged from $0.22 \$$ for Case 2 to $1.55 \$$ for Case 3. Again Case 4 was not considered because of the uncertainties in the calculated reactivity changes for the arbitrary choice of diffusion coefficients.

Since perturbation theory is a standard procedure for determining material worths for safety calculation the validity and accuracy of a number of perturbation techniques were investigated. Both transport and diffusion theory perturbation methods were used to calculate the reactivity changes between cases.

The transport perturbation calculations were performed using the $S_{4} P_{3}$ forward and adjoint fluxes because $S_{4}$ and $S_{6}$ resul ts were of comparable accuracy and $\mathrm{S}_{4}$ calculations were less costly to compute. First order and exact perturbation calculations were performed for each of the four disrupted configurations. The results of these calculations are presented in Table V.

First-order transport perturbation continuously overpredicted the magnitude of the reactivity change, for both positive and negative ihanges. This overprediction was conservative for positive reactivity changes, but 
Table V. Reactivity Changes Calculated Using Transport Perturbation Theory

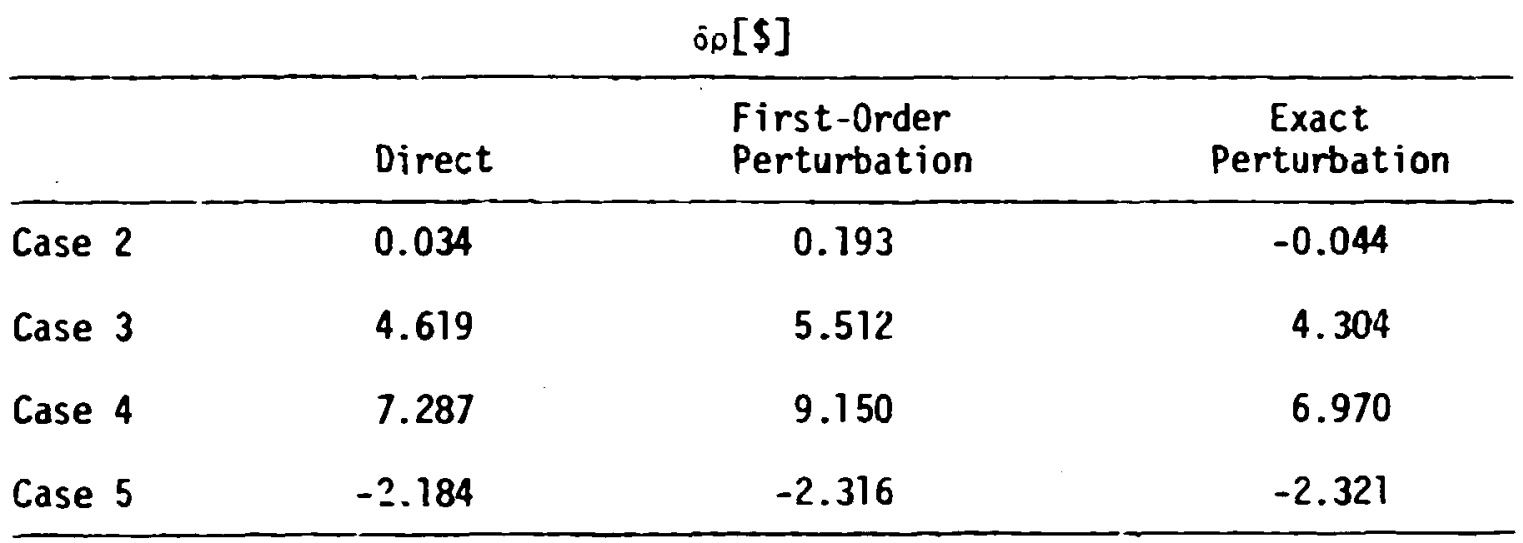

not for negative reactivity changes (i.e., the system was calculated to be further subcritical than it actually was). The use of exact perturbation theory yielded reactivity changes that were within a few percent of the direct $k_{\text {eff }}$ difference calculations. The difficulty with the use of exact perturbation theory was that the perturbed adjoint must be calculated for each disrupted configuration (a priori knowledge of the final configurations).

First-order diffusion perturbation theory fairs less well than the first-order transport perturbation theory as can be seen in Table VI. The discrepancy for some cases was as large as a factor of 5 for the magnitude of the change and in Case 2 even the sign of the reactivity change was incorrect. Again, exact diffusion perturbation theory could be used to calcuiate reactivity charges that were in goud sylegnent itr the direct diffusion keff difference results, but still not in agreement with direct transport results.

A closer examinaion of the first-order versus exact perturbation theory is presented in Table VII. The largest discrepancy was in the 
Table VI. Reactivity Changes Calculated Using Diffusion Perturbation

$\delta_{\rho}[\$]$

\begin{tabular}{cccc}
\hline & Direct & $\begin{array}{c}\text { First Order } \\
\text { Perturbation }\end{array}$ & $\begin{array}{c}\text { Exact } \\
\text { Perturbation }\end{array}$ \\
\hline Case 2 & -0.256 & -0.743 & -0.231 \\
Case 3 & 3.064 & -1.587 & 3.189 \\
Case 4 & 7.393 & 1.458 & 7.495 \\
Case 5 & -2.416 & -2.439 & 2.420 \\
\hline
\end{tabular}

Table VII. Relative Error in Reactivity Contributions Based on Diffuston Perturbation Theory $\left[\% \delta_{\rho}(\$)\right]^{\star}$

\begin{tabular}{lcccc}
\hline & Case 2 & Case 3 & Case 4 & Case 5 \\
\hline Diffusion & 23.48 & 29.48 & 43.67 & 3.99 \\
Rernoval & 0.58 & -0.52 & 2.12 & 0.97 \\
Scatter & 1.49 & 1.70 & 4.69 & 1.09 \\
Fission & 0.00 & 0.00 & -0.51 & 0.72 \\
\hline$\% \delta \rho(\$)=$ (FOP-EXACT)/EXACT $\star 100$ & &
\end{tabular}

calculation worth of the diffusior. coefficient, up to a $43 \%$ error. The largest error occurred in the case in whici a large amount of core material had been moved and the shape of the adjoint had drastically changed.

An examination of the diffusion theory first order perturbation resurts revealed that the net contribution of the removal and scattering terms, was near zero, leaving difference between the diffusion and fission térus to determine the final reactivity change. Therefore the large errors in the leakage worths were the dominant contributors to discrepancies in 
the total calculated reactivity change. It should be noted here that the leakage (diffusion) is implicitly calculated in the transport perturbation and thusly des not contribute explicitly to errors in the calculated reactivity change. It is for this reason that first-order transport perturbation tends to yield reactivity changes that are in better agreement with the direct $k_{\text {eff }}$ difference and exact perturbation results.

In view of the implicit nature of the leakage worth calculation in transport calculations, a hybrid diffucion/transport $P_{1}$ perturbation technique ${ }^{18}$ was investigated. This method involved the calculation of the partial currents for each interval from the diffusion theory scalar fluxes. These partial currents were then treated as the components of the first flux moment and folded with the $P_{1}$ scattering cross section. The remainder of the calculation proceeded as a normal transport perturbation calculation thus accounting for the leakage implicitly.-

This hybrid method was applied to each case using both the firstorder and exact perturbation approximations. The results of these calculations are presented in Table VIII. The first-order $P_{1}$ perturbation results were significantly improved over the first-order diffusion theory perturbation results. In fact they were in excellent agreement with the first-order transport perturbation results. This indicated that this hybrid diffusion/transport $P_{1}$ tecnnique riay be used to yield transport pert srbation resul ts with diffusion theory compiting expense. The $P_{1}$ method by no means calculates the correct (direct $k_{\text {eff }}$ difference) reactivity changes, but it does provide a substantial degree of improvement over standard first-order diffusion theory perturbation. No substantial improvement was noted for exact perturbation theory. 
Jable-VIII. Reactivity Changes Calculated Using Diffusion Theory Fluxes and Currents in a

Transport Perturbation Calculation

\begin{tabular}{|c|c|c|c|c|c|c|c|}
\hline \multirow{2}{*}{$\begin{array}{r}\because \cdot \\
\cdot \\
\end{array}$} & \multirow{2}{*}{$\begin{array}{c}\text { Direct } \\
\text { Transport }\end{array}$} & \multicolumn{3}{|c|}{ First-Order } & \multicolumn{3}{|c|}{ Exact } \\
\hline & & Diffusion & Trans & $P_{1}$ & Diffusion & port & $P_{1}$ \\
\hline ase 2 & 0.034 & -0.743 & 0.193 & 0.151 & & 344 & -0.216 \\
\hline ase & 4619 & -1.587 & 5.512 & 5.549 & 89 & 4.304 & 3.261 \\
\hline ise & .2 & 58 & 30 & 9.1 & 5 & 6.970 & 6.539 \\
\hline ase 5 & -2.184 & -2.439 & -2.316 & -2.412 & -2.420 & -2.321 & -2.420 \\
\hline
\end{tabular}

V. THE HETEROGLNEOUS CORE

The second phase of this study deals with a few preliminary calculations of sodiun void worth based on the ZPPR-7 mock-up of a 350 W(e) heterogeneous "parfait" core design. Since these were preliminary scoping studies, the macroscopic cross sections for the homogeneous core were used for these calculations. Included in this section are the various voided configurations that were studied and the numerical results that were obtained.

\section{A. Reactor Configurations}

Three "snapshot" configurations representing various phases of the ZPPR-7 sodium voiding experiment were chosen for this study. The configurations-considered were as follows:

Case 1 - Reference unperturbed assenioly,

Case 2 - sodium voided in the driver zones,

Case 3 - Sodfum volded in the central blanket zone. 
The square drawered ZPR matrix assenbly was modeled in $R-Z$ geometry as suggested in reference 2 .

Case 1 - The Reference Assenbly

The reference assently is depicted in figure 9. The calculational model was extended through the radial shiels $(147.253 \mathrm{~cm}$ from the centerline) where a non return boundary condition was imposed. Since all material movements in the ZPPR-7 asseably were assumed to be symetric with respect to the core midplane, only the upper half-core was modeled in the axial direction. The axial model extends from the core midplane through the upper axial shield-reflector (104.806 cm from the assembly midplane). A symetric boundary condition was applied at the midplane and non-ieturn boundary condition was imposed at the upper edge of the axial shieldreflector. The interior mesh spacing and zone map are illustrated in Figure 10. A total of 1711 mesh points was used to describe this and all the subsequent geometries. It should be noted that the $R \cdot \ddot{z}$ nodels presented here are very crude and by no means are representative of the real situation.

\section{Case 2 - The Voided Driver Model}

The intent of the sodium voided driver configuration was to model a sodium void that extends $30.48 \mathrm{~cm}$ above and below the assembly midplane in the inner two high-power to flow ratio driver zones. This configuration is described in Table IX and depicted in Figure 11. 


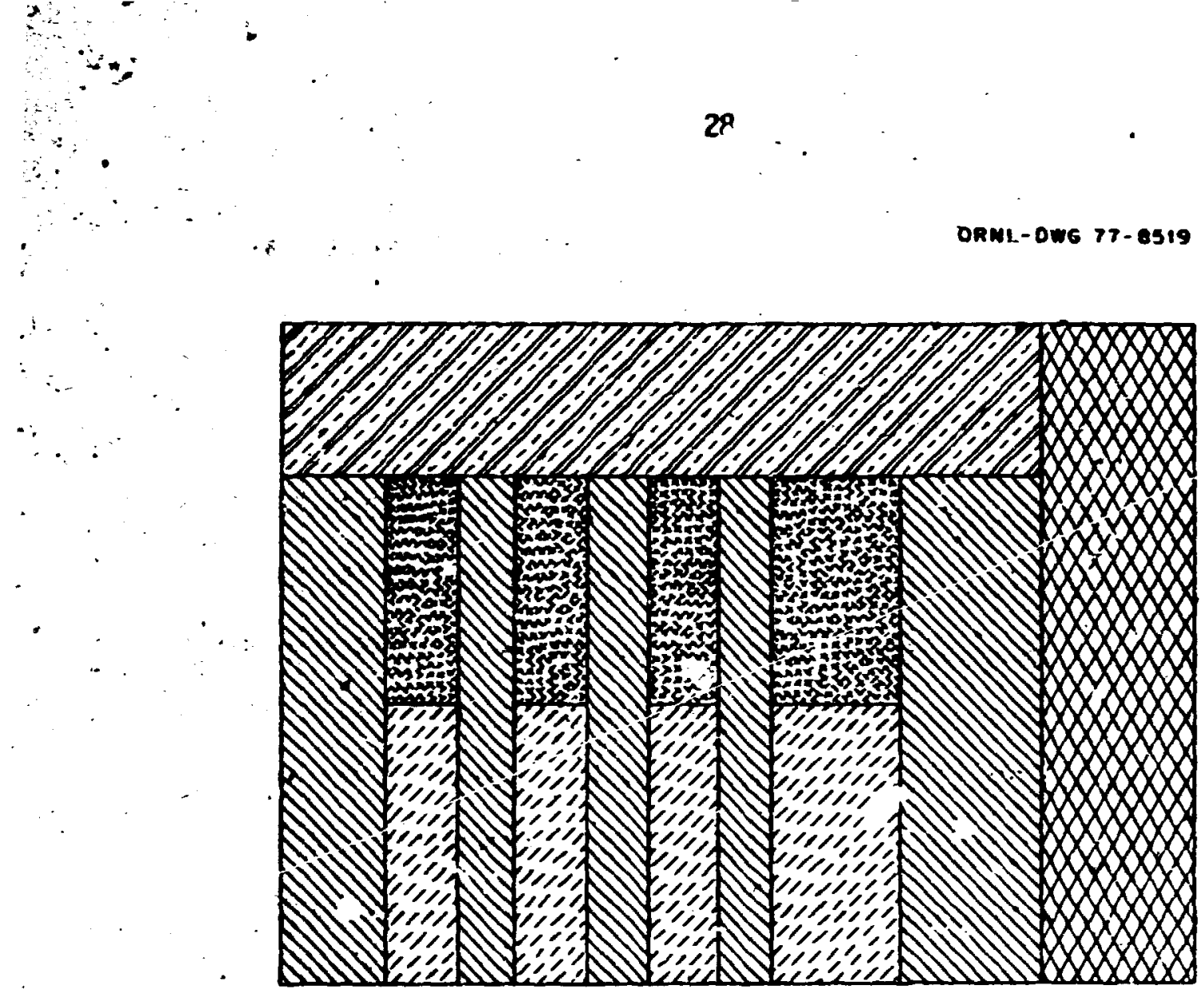

EJ DRIVÉR FUel.

D INTERMLL BLAMKET

QS AXINL REFLECTOR
AXIAL BLANKET

$\bigotimes$ radial shielo

Fig. 9. Material Map for the Case 1 Disrupted Configuration in ZPPR-7.

Case 3 - The Voided Blanket Mode1

In this configuration sodiu has been symetrically removed about the assembly midplane in the central blanket region. The voiding wass assumed to extend from $30.48 \mathrm{~cm}$ below the midplane to $30.48 \mathrm{~cm}$ above the midplane. This configuration is also described in Table $I X$. and deptcted in Figure 12. 


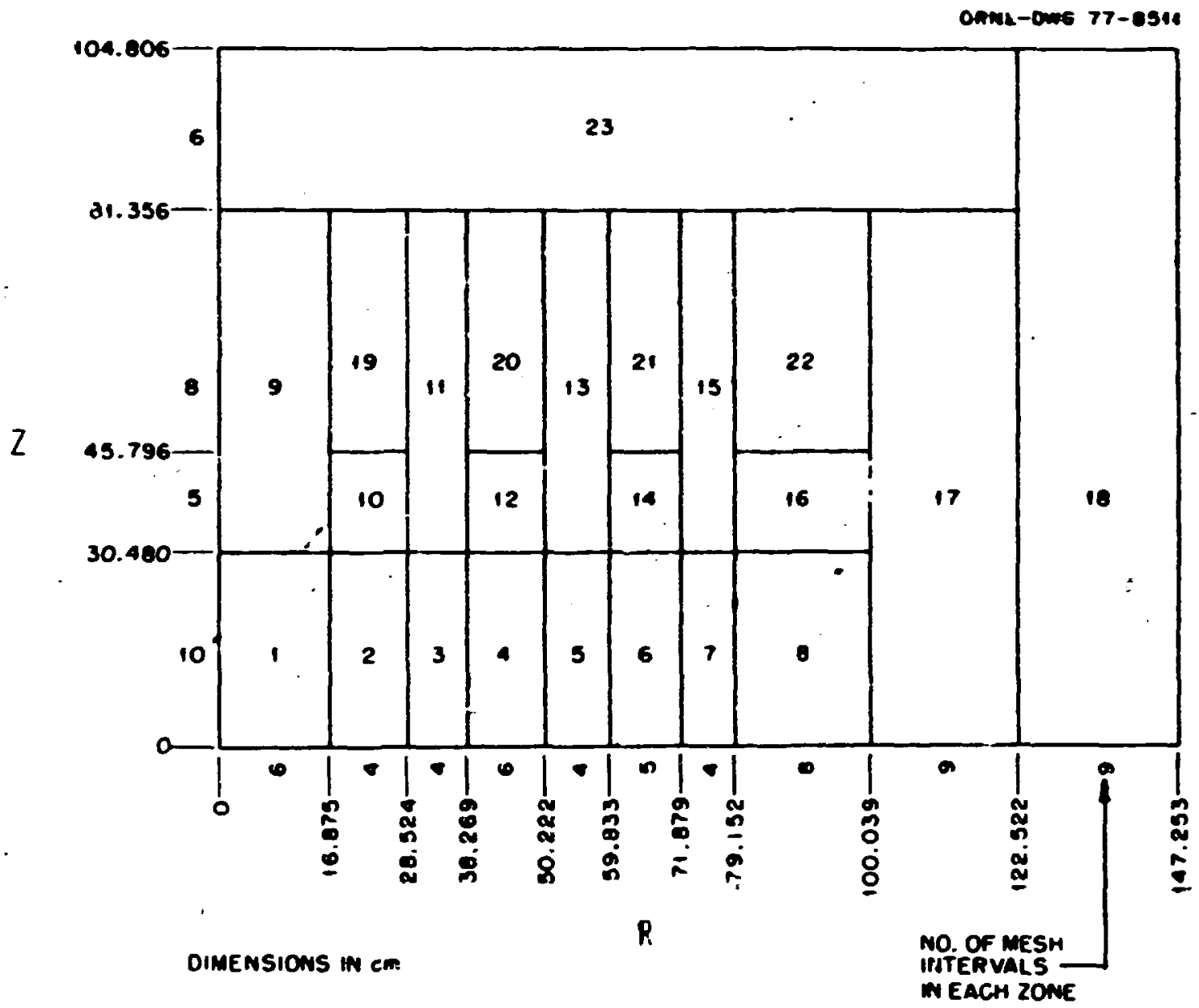

Fig. 10. Mesh Spacing and Zone Map for ZPRR-7.

Table IX. Problem Definition for ZPPR-7

\begin{tabular}{cccc}
\hline Problem ID & Effect of Interest & Quantity & Zone' Involved $^{*}$ \\
\hline Case 1 & Reference & & \\
Case 2 & Sodiun Void & $100 \%$ & 2,4 \\
Case 3 & Sodium Void & $100 \%$ & 1 \\
\hline
\end{tabular}


ORNL-OW6 Pr-esZ1

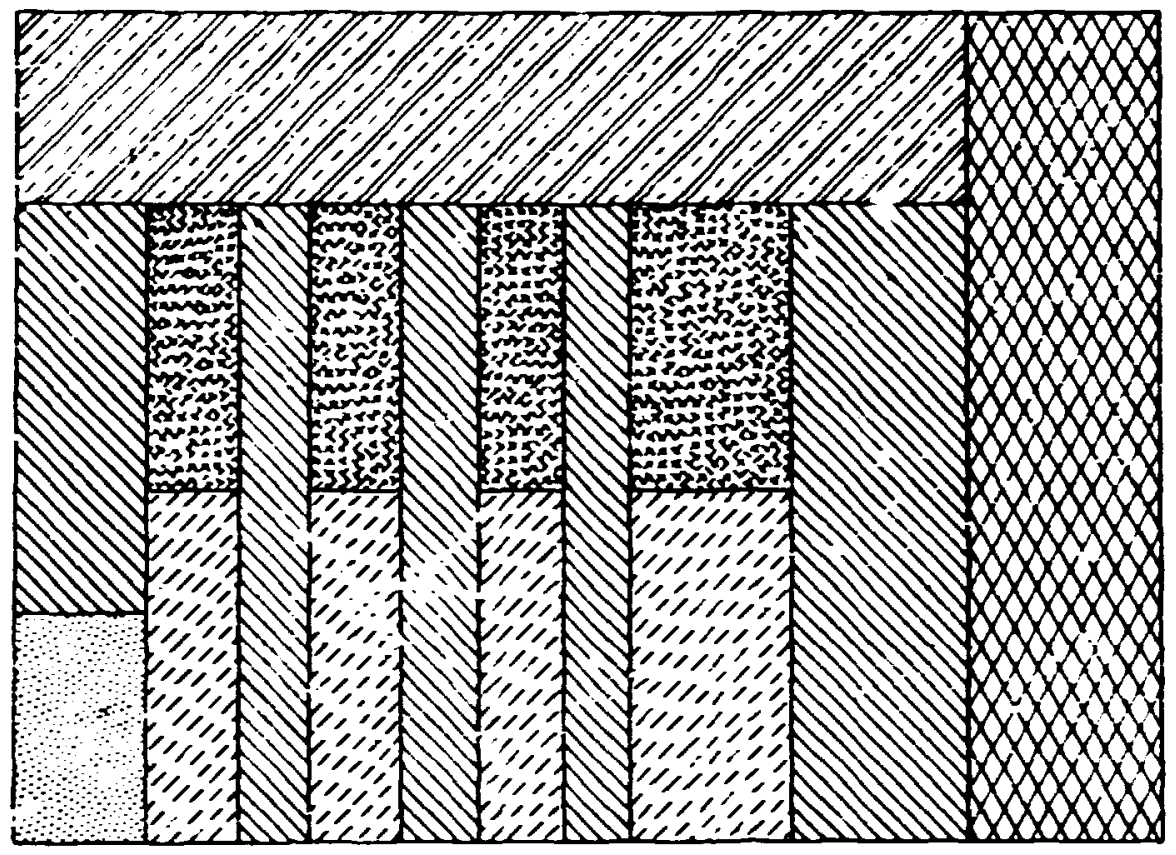

[J] DRIVER FUEL

$\$$ INTERMAL bLAMKet

鳻 AXIAi REFLECTOR
AXIAL BLAMKET

$\triangle$ racine shielo

SOOIUM VOIDEC DPIVER

Fig. 12. Material Map for the rase 3 Disrupted Configuration in 2PPR-7.

Table $X$. Calculated $k_{\text {eff }}$ for the Various Disrupted Heterogeneous Core Configurations

\begin{tabular}{lll}
\hline & $S_{4} P_{3}$ & Diffusion \\
\hline Case 1 & 0.954826 & 0.948648 \\
Case 2 & 0.957407 & 0.950956 \\
Case 3 & 0.955053 & 0.948841 \\
\hline
\end{tabular}


a single bias factor can be applied to the diffusion results to obtain the transport resuits for more disrupted configurations tecause only sall perturbations. to the system's geometry were considered. Large movewents of-core interial could reveal greater transport/diffusion discrepan"cies; however, for the specific cases addressed in this study a constant bias factor did exist.

Prior to discussing the disrupted core results in depth, four points concerning the reference core calculations are of interest and are presented here.

- In all the fertile (blanket) regions, diffusion theory consistently gave a harde. spectrum than transport theory.

- In all fissile (driver) regions, diffusion theory consistently gave a softer spectrum than transport theory.

- The total flux was depressed more in the fertile regions for the transport calculation than for the diffusion calculation.

- The U-238 capture rate followec the same trends as the total flux.

The direct $k_{\text {eff }}$ difference reactivity changes for the two disrup:ed cases are presented in Table XI. As in the homogeneous case, diffusion theory predicted the assembly to be in a less reactive stats than that predicted by transport. theory. There was a $10 \%$ underprediction of the reactivity chunge in the voided driver calculation and a 14: underprediction in the voided blanket configuration. The effects of this, discrepancy are illustrated in Table $X I I$. The $C / E$ values calculated using diffusion theory taken from reference 2 and the $T / 0$, transpert/ diffusion ratios, were taken from this report. The inclusion of $t^{\prime} 1 \theta$ 
Table XI, Calculated Reactivity Chanqes for the Varicus Disrupted Heterogeneous Core Configurations $\delta \rho(\$)$

\begin{tabular}{lcc} 
& $\mathrm{S}_{4} \mathrm{P}_{3}$ & Diffusion \\
\hline Case 2 & 0.882 & 0.799 \\
Case 3 & 0.078 & 0.067 \\
\hline$B_{\text {eff }} \equiv 0.0032$ & &
\end{tabular}

Table XII. Transport Corrected C/E for ZPPR-7.

\begin{tabular}{llll}
\hline & $C / E^{a}$ & $T / D^{b}$ & $C / E^{c}$ \\
\hline Case 2 & 0.865 & 1.104 & 0.955 \\
Case 3 & 0.930 & 1.164 & 1.083 \\
\hline
\end{tabular}

${ }^{a}$ C/E values calculated using diffusion theory, see reference 2.

$b_{\delta \rho}$ Transport/ $\delta_{\rho} D$ iffusion.

${ }^{C}$ Transpor: adjusted $C / E$. (C/E X T/D)

transport effects tends to alleviate a large fraction of the calculational disagreement with the experimelit. It should be kept in mind, however, that these results only indicate trends since the ator. densities and cross section treatments used for the heterogeneous core studies were not rigorous.

\section{CONCLUSIONS}

The overriding conclusion of this study was that for all cases investigated diffusion theory and first-order diffusion perturbation theory were inadequate for the calculation of the reactivity state of severely disrupted homogeneous LMFBR cores. There appears to be no 
single bias factor that can a priori be calculated and app?ied to the calculated multip]ịcation factor to obtain equivalent transport theory results. Similariy there are no single bias factors existing that can be applied to the reactivity changes calculated using diffusion theory or diffision perturbation theory tc obtain equivalent transport theory results.

When compared to transport theory, diffusion theory also underpredicted keff for heterogeneous, parfait, core calculations. A single bias factor did exist that would be applied to the diffusion theory results to obtain transport results for the situation in which various parts of the core were volded of sodium. This dees not necessarily mean that a single bias factor could be a priori calculated and applied to diffusion results to obtain transport results for severe core disruptions. The sodium voiding cases represented relatively small perturbations to the system with minimal material motion. Large movements of core material could reveal greater transpart/diffusion discrepancies. This is presently being investigated.

The inajor failing of diffusion theory was in its cons istent overprediction of leakage from zones of low density. This effect was particularly evident in the first order diffusion perturbation results where errors as large as $43 \%$ in the calculation of leakage (difiusion coefficient) worths existed. First order trarisport perturbation th sory, where the leakige terms are accounted for implicitly gave results that were in better agreement with direct $k_{\text {eff }}$ difference calculations, however, the calculated charge in. reactivitis (buth positive and negative) was consistently overpredicted. For regative insertions this was a nonconservative approximation. 
A numer of other investigators at otner insta!lations have also performed calculations sinilar to those carried out in chis study. Recently, Cahalan at Argonne National Laboratory perforred a number of numerical experiments $^{19}$ and obtained results that agree both qualitatively and quantitatively with the results of this study. His results support the results presented here in that transport effects, especially, in the calculation of neutron leakage from low density regions must be included in fast reactor safety neutronics. He has investigated a method that incorporates transport calculated leakages in diffusion theory calculations and has shown that this thod gave significantly improved diffusion theory results. Also at ANL, work is under way to investigate the applicability of directional-dependent diffusion coefficients 20 to remedy the failure of classic diffusion theory to correctly calculate neutron leakage.

nuring the course of this study a hytjrid transport/diffusion perturbation theory was developed. The $P_{1}$ perturbation method offers first order transport perturbation theory accuracy with diffusion theory computation times. This hybrid calculation while not being a solution to all the safety related neutronic problems does orovide a means of improved accuracy at low computational costs.

It is not clear, however, which approach should be caken, whether the diffusion theory approximations should be eliminated completely and a low order transport $\left(S_{4} P_{0}\right)$ method be perfacted for fast reactor safety related neutronics calculations, or a hybrid diffusion/t.ransport methods such as Cahalan's in conjunction with a hybrid pcrturbation method such as the method presented in this study should be pursued for impioving fast, reactor safety neutronics calculations. The low order transport method would be 
preferable as it has the potential of handling more severe streaming and anisotropy effects where diffusion theory and hybrid $P_{1}$ theory are limited in their ability to calculate these effects.

\section{ACKNOALEDEMENTS}

The author would like to acknowledge the efforts of P. B. Fox in obtaining the Monte Carlo results presented in this rejort and also M: A. Thoades and W. W. Engie, Jr., for the discussion of the "superweighted" differencing scheme that is presented in the appendix. The author would also like to thank R. L.' Childs for many discussions concerning the $P_{1}$ perturbation tecnn ique. The efforts of $C$. P. Tramell and B. 0 . Neeley in typing this manuscript are greatly appreciated. 


\section{REFEREICES}

1. H. R. Bohl, et al., An hna'ysi- of Masnsient Undencooling and Pronsient Overpower Accidents without Ssrom on the Clinsh River Breeder Reactor, ANL/RAS 75-29, Argonne National Laborạtory (July 1975).

2. Twentieth Quarterly Report: Critical Experiments and Analysis, JulySeptember 1976, GEAP-13771-20, General Electric Company (October 1976).

3. D. L. Selby and H. E. Knee, "The 7 and 45 Group CRBR Cross Section Libraries," letter to G. F. Flanagan, May 27, 1977.

4. C. R. Heisbin, R. H. Roussin, J. E. White, and R. Q. Hright, Specification for Pseudo-Composition-Independent Pine-Grout LAFBR Heutron-Gamma Libraries at ORNL, ORNL/TM-5142 (ENDF-224) Oak Ridge National Laboratory (December 19;5).

5. N. C. Paik, et al., Physics Evaluations and Applisations Quarterly Progress Report Eriding Juíy 31, 1974, HARD-XS-3042-7 (July 1974).

6. N. M. Greene, 1. L. Lucius, L. M. Petrie, W. I. Ford III, J. E. White, and R. Q. Wright, AMPX: A Modular Code System for Generating Coupled Multigroup Neutron-Guma Libraries from ENDF/B, ORNL/TM-3706 (1976).

7. G. C. Haynes, The AXMIX Progran far Cross Section Mixing and Library Arrargement, ORNL Central Files Report 74-12-2, Oak Ridge National - Laboratory (December 1974).

8. W. A. Rhoades and F. R. Mynatt, The DOT-III Two Dimensional iriscrete Ordinates Transport Code, ORNL/TM-4280 (September 1973). 
9. D. R. Vondy, T. B. Fowler, and 6. H. Cunningham, VENTURE: A Code Block for Solving Multigroup Neutronics Iroblems Applying to Pinite-Differenee Diffusion-Theory Approx mation to Neutron Tronsport, ORML/TMA-5062 (October 1975).

10. D. R. Ferguson, K. L. Derstine, R. C. Borg, and T. A. Daly, "Optimized Iteration Strategies for Fast Recctor Finfte-Difference Diffusion-Theory Codes," Trans. Am. Wuc. Soc. 22: p. 247 (November 1975).

11. D. R. Ferguson, T. A. Daly, and R. H. Schaefer, EX2, A Quasistatic Multidimenoional Multigroup Diffusion Theory Code with Feedbaok, FRA-TM-87, Argonne National Laboratory (April 1:976).

12. W. A. Rhoddes, Conments on the DOT 3.5 and DOT 4 Codes.

13. R. L. Childs, VIP - A Computer Code Using Two Dineneional Discrete Ordinates Calculations for Cross Sestion Sensitivity Analysis, UCCND/CSD-1 (to be published).

14. R. A. Lillie, "Transport Perturbation Code," 'letter to G. F. Flanagan, (March 17, 1977).

15. E. T. Tomlinson, "Diffusion :Theory Perturbation Using DOT Fluxes," letter to G. F. Flanagan (May 3, 1977).

16., Ire'iminary Safety Analysis Report for the Clinch River Breeder Reactor Plant, Project Management Corporation.

ii. L. M. Petrie and N. F. Cross, KENO-IV, An Improved Monte Carlo Criticality Progran, IPNL-4938, Oak Ridge National Laboratory (November 1975).

18. R. L. Childs, Oak Ridge Naticnal Laboratory, personal comunication, April 1971. 
19. J. E. Cahalan, An Iterative Diffision Theory Method for the Incorporation of Trunsport Effects in Fast Reactor Safety Neutronics, ANL/RAS 76-17, Argonne National Laboratory (May 1976).

20. P. Benoist, "Theories due Coefficient de Diffusion dans un Réseau Compartant des Cavités," Centre d'Etude Nucléaires-Scalay Rep. CEA-R-2278 (1964). 
0
20
25
25

$=$

$\therefore \therefore$
$\therefore-\because$

Appendix.

Hos 


\section{A NEW WEIGHTED-DIFFERENCE FORMLATION FOR DISCRETE-ORDIMATES CALCULA? IONS}

One of the shortcomings of the method cf discrete ordinates has been a tendency to generate negative estimates of inherently positive fluxes due to over-extrapolation. ${ }^{2}$ The complexity of practical transport problems is such that mesh refinement is only a partial remedy. This paper shows a new formulation of an old approach wich ensures positive results shile retaining satisfactory accuracy.

In the two-dimensional discrete-ordinates transport equation,

$$
\mu\left(A_{i+1} N_{i+1}-A_{j} N_{j}\right)+{ }_{n} B\left(N_{j+1}-N_{j}\right)+\left(r_{m+1} N_{m+1}-r_{m} N_{m}\right)+o N V=S V,
$$

three of the N's are known from boundary conditions, but assumptions must be made describing the variation of flux across the mesh cell to el iminate three more unknowns. The weighted-difference method for solving Eq. (1) uses three parameters, $a, b$, and $c:^{3}$

$$
N=a N_{i+1}+(1-a) N_{i}=b N_{j+1}+(1-b) N_{j}=c N_{m+1}+(1-c) N_{m} .
$$

With these,

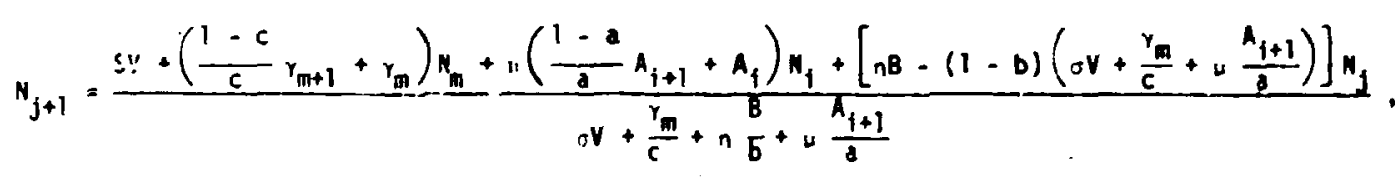


and $n_{i+1}$ and $n_{n+1}$ can be found similarly. When $a=b=c=1 / 2, E q$. (3) is equivalent to the "diamond-difference" model and assumes a linear variation in flux across the wesh cell. The diamond-difference nodel provides excellent accuracy for swall, tesh sizes, and values of $a, b$, and $c<1 / 2$ are not considered. Unfortunately, the diamond-difference model generates negatives for jesh sizes which are not uncomnon in real problens, even though the true result is positive if $S$ is positive. With $a=b=c=1$, the "step" model is obtained, equivalent to assuming $N=N_{i+1}=N_{j+1}=N_{n+1}$. This gives inherently positive fluxes, and values of $a, b$, and $c>1$ are not considered.

For many years, a "fix-up strategy" has been used, in wich the diamonddifference model is used unless one of the extrapolated fiuxes is negative. In that case, all of the fluxes are recalculated using the step model.4 Another variation involved setting the negative flux to 0 and recalculating the other values. 5 Unfortunately, all fix-up methods can lead to spatial flux distortions and "model-switching" oscillation between iterations, which thwart convergence.

Positivity can also be ensured by adjusting b such that:

$$
S V_{\theta_{s}}+\left(\gamma_{n} N_{m}+\mu A_{j} N_{j}\right) \theta_{N}+\left[n B-(1-b)\left(o V+2 \mu A_{i+1}\right)\right] N_{j}>0
$$

where $\theta_{s}$ and $\theta_{N}$ are arbitrary multipliers bounded by 0 and 1 .

A solution could be found with $\theta_{S}=\theta_{N}=1$, but this can lead to degeneracy in certain cases, producing numbers near 0 which thwart convergence once again. The DOT III code used $\theta_{S}=1$ and $\theta_{N}=\theta$. This provided good results for deep-fenetration problems, but failed for criticality calculations due to excessive leakage. Consideration of a difficult reactor cell problem 
reveals why this happens. Cell problems typically have tall, narrow space cells. In zones having no source, (4) requires use of the step model along the height of the $2 e l l$, even though flow across the vertical boundaries would control the actual result of (3) and produce a satisfactory value.

The DOT IV code includes a "$\theta$-weighted" option in which $\theta_{S}$ and $\theta_{\mathbf{N}}$ are arbitrarily set to 0.9 . This allows the accurate linear notel to be used where it is adequate and gives a smooth transition to the step model when the linear model actually breaks down. Either the DOT III or $\theta-$ weighted method cost roughly $15 \%$ more per iteration tian the linear model with step fix-up, but smooth, rapid convergence is found for problens which would otherwise oscillate. Table Al shows the convergence of a cell problem using the methoos described, as well as one where the $\theta$ weichted model is used as a fix-up to the linear model. The requirement for weighted difference in problems of this class is apparent.

Table A2 shows that the $\theta$-weighted model compares favorably with the fix-up models in matching the Monte Carlo result, which is assumed accurate. The new model, then, giver the desired smooth convergence wi thout compromising accuracy. 
Table Al. Flux-Convergence Reached Using Various Nuserical Models*

\begin{tabular}{ccccc}
$\begin{array}{c}\text { Outer } \\
\text { Iterations }\end{array}$ & $\begin{array}{c}\text { Linear/ } \\
\text { Step }\end{array}$ & $\begin{array}{c}\text { Linear/ } \\
\text { Heighted }\end{array}$ & $\begin{array}{c}\text { DOT III } \\
\text { Heighted }\end{array}$ & $\begin{array}{c}0 \text { - } \\
\text { Weighted }\end{array}$ \\
\hline 1 & 1.2 & 1.1 & 0.3 & 0.5 \\
2 & 0.6 & 0.5 & 0.1 & 0.2 \\
3 & 1.2 & 1.6 & 0.7 & 0.05 \\
4 & 0.5 & 0.5 & 0.03 & 0.04 \\
5 & 0.2 & 0.4 & 0.03 & 0.01 \\
6 & 0.3 & 0.09 & 0.01 & 0.01 \\
7 & 0.3 & 0.3 & 0.006 & 0.006
\end{tabular}

Convergence for the mth inner iteration is defined as:

$$
\frac{\phi_{m}-\phi_{m-1}}{\phi_{m}}
$$

Table A2. Values of K-Effective For a Difficult Cell Problem Using Vorious Numerical Methods

\begin{tabular}{cccccc}
\hline Example & Code & $\begin{array}{c}\text { Energy } \\
\text { Groups }\end{array}$ & Method & K-Effeciive \\
\hline 1 & DOT IV & 11 & Limear wfth step fix-up & 0.996 \\
2 & DOT IV & 11 & Linear with weighted fix-up & 0.996 \\
3 & DOT IV & 11 & DOT III style weighted difference -0.930 \\
4 & DOT IV & 11 & 0-weighted difference & 0.991 \\
5 & DOT IV & 51 & Li. . with weighted fix-up & 0.998 \\
6 & MORSE & 51 & Multigroup Monte Carlo & $0.988 \pm 0.015$ \\
\hline
\end{tabular}

Note (1): Keff was converged to \pm 0.001 in the DOT cases.

(2): If 0.002 is taken as an "11-group library correction," based on exainple 5 vs :xamplo 2 , the 0 -weighted result for 51 groups would be 0.993 , compared wi th the MORSE result $0.988 \pm 0.015$. 


\section{APPENDIX REFERENCES}

(1) W. A. Rhoades and W. S. Engle, Jr.: "A New Weighted-Cifference Formulation For Discrete-Ordinates Calculations," submitted to ANS Winter Meeting, San Francisco, CA., November 1977.

(2) B. G. Carlson arid K. D. Lathrop, "Transport Theory - The Minthod of Discrete Ordinates," Los Alamos Scientific Laboratory, LA-325I-MS Revised, 1965.

(3) K. D. Lathrop, "Spatial Differencing of the Transport Equation: Positivity is Accuracy," J. Comput. Physs., 4, 475 (1969).

(4) F. R. Mynatt, et al, "Development of Two-Dimensional Discrete Ordinates Transport Theory for Radiation Shielding, "Union Carbide Corporation, CTC/IMF-952 (196S).

(5) K. D. Latiorop and F. H. Brinkley, "THCTRAN-II: An Interfaced, Exportable Version of the TWOTRAN Code for Two-Dimensiona i Transport," Los Alamos Scientific Laboratory, LA-4848-MS (1973). 